\title{
Use of a Comic Book to Assist Pharmacy Student Learning of the Affordable Care Act (ACA)
}

\author{
Jagannath M. Muzumdar, PhD; Somnath Pal, PhD
}

College of Pharmacy and Health Sciences

St John's University

\section{ABSTRACT}

Purpose: To assess the pedagogical effectiveness of a comic book in pharmacy student learning of the Affordable Care Act (ACA).

Methods: Comparative-group, matched pre-posttest survey design was used to measure pharmacy students' comprehension of ACA. PharmD students (P-1year) from two sections of a Pharmacy and US Healthcare course participated in this study. Treatment group students received a comic book on ACA. The comparison group received the textual information, without pictures, from the book in a typed document. A posttest survey was administered later in the semester, before the instructor discussed ACA in class. Fourteen questions, developed from the information in the book and document, assessed pharmacy students' comprehension of ACA. Response options included a visual analogue scale. Independent sample t-test was used to assess the differences in the mean pre-posttest scores between the two groups.

Results: A total of 103 ( $n=49$ comparison vs. $n=54$ treatment group) students completed the survey. No statistically significant differences were found in the pre-test mean scores between the groups. Differences in the pre-post test mean scores of treatment group were significantly higher than the differences in the mean scores of the comparison group. Students agreed that the comic book format gave them a better understanding of ACA and increased their interest in learning more about the Act.

Conclusion: Comic books were found to be effective in student learning of the ACA. The positive response from students highlight the point that pharmacy faculty could use comic books as supplemental reading in pharmacy courses.

Keywords: Comic(s), graphic novels, comics, education, pharmacy, Affordable Care Act

\section{INTRODUCTION}

According to the Centers for Disease Control and Prevention (CDC), nearly 43 million Americans were uninsured in the year 2013. ${ }^{1}$ The Patient Protection and Affordable Care Act (PPACA) also known as the Affordable Care Act (ACA) or Obama Care (P.L. 111-148), was aimed primarily at reducing the number of uninsured by expanding the healthcare coverage to millions of Americans without health insurance. ${ }^{2}$ The law has provisions that required Americans to either buy/obtain health insurance or pay a penalty/tax. ${ }^{3}$ But, to make an informed choice in choosing health insurance plans, an uninsured American today would need to have a basic understanding of implications of the terminologies the ACA mandates to be included in the health insurance plans. However, the primary beneficiaries of the provisions in healthcare reforms are mostly people with low socio-economic status, low education levels, the young, and people of color who have limited health insurance literacy. ${ }^{3-4}$

Health insurance literacy is defined as "the degree to which individuals have the knowledge, ability, and confidence to find

Corresponding author: Jagannath M. Muzumdar, PhD

Associate Professor

Department of Pharmacy Administration and Public Health

College of Pharmacy and Health Sciences

St John's University

Tel: +1 (718) 990-2945; Fax: +1 (718) 990-6316

Email: muzumdaj@stjohns.edu and evaluate information about health plans, select the best plan for their own (or their family's) financial and health circumstances, and use the plan once enrolled"2 Understanding how health insurance plans work is a daunting, complex task. Potentially, it is even more complicated for the diverse group of uninsured individuals. A survey of people eligible to enroll in insurance plans, showed that there was a lack of understanding of certain basic health insurance terminologies. ${ }^{5}$ Another recent telephone survey of 1008 US adults, found that more than half of them could not accurately identify at least one of three common health insurance terms: premium, deductible and co-pay. A third, 34 percent, thought a premium was an expense at the time of receiving medical service or a prescription; more than a quarter, 27 percent, thought a co-pay was the cost of obtaining insurance; and 12 percent did not know a deductible is the money one pays before an insurance company makes payments. ${ }^{6}$

These findings along with prevalence of highly diverse sociodemographic characteristics (such as age, ethnicity, poverty level, and employment status) among the uninsured can be indicative that understanding of the health insurance terminologies is likely to be more challenging for individuals with limited health insurance literacy. ${ }^{3-7}$ Reports from the National Academy of Medicine (NAM-formerly called the Institute of Medicine) and the American Institute for Research have concluded that, success of healthcare reforms such as ACA in increasing coverage for millions of uninsured Americans would depend on consumers understanding of the elements of health insurance market. ${ }^{2,8}$. Most of the published literature on 
ACA requires a lot of thought and concentration to read and, is extremely complex to understand. Browsing through the information provided on various online sources can be difficult. Trying to deduce all of the information about insurance plans can be, at best, time-consuming and, at worst, undecipherable. Also most people either do not read or do not have to read the actual Act to understand the benefits. Most depend on literature and information leaflets available online or dispensed at local health exchanges.

Pharmacists are considered one of the primary sources of healthcare information. ${ }^{9}$ Providing health education is an important professional role of the pharmacist and may include more than just educating consumers about the medications that are dispensed. As a key point of access for patients (during the medication dispensing process or otherwise), pharmacists are in a position to effectively educate their patrons about healthcare reform such as ACA. For this reason the pharmacists should have adequate knowledge about the key provisions of the Act. The Colleges and Schools of Pharmacy in the United States have started discussing the relevant sections of ACA in their curriculum to increase the awareness of its students to the different aspects of the evolving healthcare system. At a College of Pharmacy located in the North-East region of the country this information on the ACA is covered in a required course for students in the first professional (P-1) year of the Doctor of Pharmacy (PharmD) program. The purpose of this study was to evaluate the effectiveness of an educational tool used in the course for conveying the information about the ACA.

\section{Comic Books in Classrooms}

Potency of visual aids in education has been well established through extensively published research. Evidence supports the contention that student learning is affected positively when text and illustrations are presented together. ${ }^{10,11} \mathrm{~A}$ form of visual communication that combines both, visuals and text, is comics. Comic books combine content through written word and artwork to create a narrative that appeals to readers not only artistically, but also informatively. Scholarly articles assessing the use of comic books as a pedagogical tool have found that they engage students in the topic being covered, motivate them to read, help them remember content, and make the whole learning process fun. ${ }^{12-17}$

English Professor Rocco Versaci used comics to challenge students to critically examine the very definition of literature. ${ }^{12}$ He mentioned that, the use of comics energizes students in the respective classes, engages students in the information being presented, and builds their analytical and critical thinking skills. ${ }^{12}$ Gerde and Foster have used comic books in their classroom as discussion topics ranged from leadership and technology to discrimination and environmental issues. ${ }^{13}$ They have argued comic books are a legitimate literary form for study and could be used to communicate, discuss, and critique issues in business ethics and other social issues in management. ${ }^{13}$ Short and Reeves present graphic novels as an attractive medium to communicate business concepts. ${ }^{14}$ The authors have explained how and why graphic novels are useful tools to cover management concepts for business students. ${ }^{14}$ Hosler and Boomer report data suggesting comic book stories can play a significant role in conveying content in a coherent manner and, in the process, improve the attitudes non-science majors have towards biology. ${ }^{15}$ Nagata used panels of manga (Japanese comics) to supplement explanations of biochemical terms and topics in biochemistry classes. ${ }^{16}$ Their results showed the use of manga helped students learn. Just as other researchers have reported, Nagata found the use of comics in biochemistry made the classes less serious and increased the number of students interested in the subject. ${ }^{16}$ Muzumdar used comic book as a supplemental reading to assist student learning of the dimensions of patient-centered care. Student comments indicated that the visual rich content of the comic books proved to be an enjoyable and, innovative tool in classroom learning. ${ }^{17}$ Student responses to the activity of comic book reading were overwhelmingly positive. ${ }^{17}$

The success of this format can be attributed to a number of reasons. Comic books are easily accessible for a variety of learners; they are shorter, quick to read, and provocative in ways that are beneficial to student learning. Comic books could be a "fresh" way of presenting information which could encourage students to read the materials, understand it, and reflect upon it.

\section{METHODS}

Aim

Although this literature shows the success of comic books as an educational tool in a number of different academic settings, the potential of this untapped resource as an instructional method has not been quantitatively evaluated in pharmacy literature. To support our contention on the use of comic books in pharmacy courses an exploratory study was designed to assess the pedagogical effectiveness of a comic book in student learning of the ACA. The primary objective of this study was to assess the change in perceived confidence of pharmacy students in their understanding of the relevant sections ACA using the comic versus the traditional instructional aides.

\section{Design}

At a University located in the North-East region of the country, PharmD students in their first professional (P-1) year are required to take a three-credit course titled "Pharmacy and US Healthcare Environment". This course is designed to introduce the students to the U.S. health care delivery system and explore the social, political, and economic factors which influence the flow of pharmaceutical products and services within the system. Special emphasis is placed on the role and function of pharmacy in the new paradigm of ever-changing health care. 
An overview of the current structure and financing is provided. Focus is given to the public and private sectors of health care, the major players, the pharmaceutical industry, third party plans, and managed care. One of the topics covered in this course is the ACA.

Depending on the schedule of classes, the academic advisor for the (P-1) year randomly assigns students to different sections. Five sections of this course ( $\sim 50$ students/section) were offered in the fall semester of 2014. The author of this paper was the instructor for two of the five sections offered that semester. PharmD students (P-1year) from these two sections participated in this study. The class met twice a week for an hour and thirty minutes for 14-weeks.

Several different teaching methods were used in this course. For most classes, a lecture format ( $75-85$ minutes of the class time) was used followed by 5 -minute reflection papers and discussion of the answers provided by the students. In these 5minute reflection papers, students provided their responses to a question posed by the instructor based on the topic covered on that day. Videos and guest speakers were also incorporated in the activities designed to cover the course content in the two sections covered by the author. The innovative part of the course was the use of comic book as a supplemental reading for conveying the information on the different aspects of the ACA. The comic book is titled "Health Care Reform: What It Is, Why It's Necessary, How It Works" by Dr. Jonathan Gruber. ${ }^{18}$ The author, a MIT health economist Dr. Jonathan Gruber helped to write the 2006 Massachusetts health care law and was an adviser to President Obama during the drafting of the ACA.

In the 151-page comic book, Dr. Gruber attempts to clarify information and combat misconceptions about ACA. The book aims to answer specific issues, such as why health-care reform is important, what the individual insurance mandate is, and whether or not people will be required to buy health insurance that they cannot afford. This comic book walks readers through the history of health care in the United States, the basics of the law and, what it means for patients. ${ }^{18}$

During the semester students in one of the sections (treatment group) were asked to read the comic book. A copy of the book was given to every student in the treatment group. The comparison group, i.e., students in the other section, were provided the textual information, without pictures, from the book in a typed document (Figure 1). Similar to the treatment group, the typed document was given to every student in the comparison group. A pre-post survey was administered to assess students understanding of ACA concepts. This assignment accounted for $5 \%$ of their overall grade in the course. Following the posttest, portions from the book, such as "Cadillac Tax", "ACA provisions for prescription drugs and donut hole" and, "tax credits for employers providing insurance to their employees," were later discussed in class when the topic of ACA was covered by the instructor.

\section{Pre-Post Questionnaire}

The study population consisted of 105 PharmD students in the first professional year (51-students in the comparison group and 54-students in the treatment group). A pre-questionnaire was administered at the start of the fall semester (first week of September 2014). Following the pretest, the copies of the book and typed document were given to the treatment and comparison group, respectively. Students were asked to read the material (book or typed document) given to them. They were informed that, there would be a follow-up activity towards the end of the semester when the instructor would cover information on health insurance. A post-questionnaire was administered later in the semester (first week of December 2014), before the instructor discussed ACA in class. During this three month period between September-November, the course instructor for the two sections did not have any discussions about the Affordable Care Act. Students who attended class on the days the questionnaires were administered were the participants of the study.

The data instrument for this study was a 14 -item selfadministered, paper-pencil based survey questionnaire developed from the information covered in the book and document. Four out of the fourteen items in the questionnaire were general questions about rising healthcare costs and the related effects on the healthcare system. For example, how would you rate your understanding of how rising healthcare costs can affect people (healthy as well as unhealthy). The majority of the items (10 out of 14 items) in the questionnaire were specific to the aspects of the ACA i.e., how would you rate your understanding of what is the feature of the "Cadillac Tax" in Affordable Care Act (ACA). The questionnaire was developed to assess pharmacy students' understanding of the aspects of the ACA after reading the book or textual document.

Response options for this study included the visual analogue scale (VAS). ${ }^{19-21}$ Operationally, a VAS is usually a horizontal line, of fixed length with no markings (5 inches in this study), anchored by word descriptors at each end of the continuum. ${ }^{21}$ The anchors for this study were, "No understanding of the topic" to "Complete understanding of the topic". Students were instructed to mark on the line the point that they felt best represented their response to that particular question. The VAS score was determined by measuring from the left hand end of the line (No understanding of the topic) to the point of the student mark.

Questionnaires for each student were assigned a unique identifier to match the pre- and post- surveys. This identifier was coded and known only to the researcher. The questions did not contain any personal or sensitive information unrelated to 
the material covered in the reading material. Confidentiality and anonymity of the responses were maintained. The research methodology was approved by the Institutional Review Board at the University.

\section{Data Analysis}

Responses to the items were measured with a scale and the number was entered next to the item. Data was analyzed using Statistical Package for Social Sciences (SPSS) version 21.0. Cronbach's alpha values were calculated for the entire questionnaire to determine its reliability. ${ }^{21-24}$ Content validity was assessed through review by two experienced faculty members in College of Pharmacy who have taught the course of "Pharmacy and US Healthcare Environment" in the past and were instructors for other sections of the same course. ${ }^{21-24}$ The faculty evaluated the questionnaire for its content, ordering of items, wordings of items, clarity of items, respective response categories, and aesthetics of the questionnaire. Their feedback was used to make minor changes to the wording of the questionnaire. The changes included formatting modifications where the questionnaire was made smaller and more concise. Independent-sample t-test was used to compare means of the two groups. The significance level for the analysis was set at $\mathrm{p}<0.01^{22,24}$

\section{RESULTS}

A total of one-hundred and five PharmD (P-1 year) students were enrolled in the two sections of the course in which the questionnaires were administered. However, due to absences on the days when the questionnaires were administered only 103 ( $n=49$ comparison vs. $n=54$ treatment group) questionnaires could be paired for final analysis. The Cronbach's $\alpha$ estimate of internal consistency was 0.88 for the pretest scale and 0.95 for the posttest scale. The mean interitem correlations were 0.33 and 0.58 for the pre-and post-test questionnaire items, respectively, suggesting sufficient covariation to warrant formation of scales. ${ }^{23}$

There were no statistical significant differences in the presurvey mean scores for students in the two groups. Students started at the same level of understanding of the different aspects of ACA (Table 1). Posttest mean scores showed students' scores on the posttest increased for all items of the questionnaires (Table 1).

Results of the independent samples t-test comparing the mean rating change of the treatment group (comic) and comparison group (no comic) found a significant difference in the mean rating change of the two groups (Table 1). This significance was found for items that were specifically asked to assess student understanding of the different aspects of the ACA. For example, for the question, "how would you rate your understanding of what is the feature of the 'Cadillac Tax' in Affordable Care Act $(A C A)^{\prime}$ " students' mean rating change from pretest to posttest scores for treatment group was 1.54, whereas the mean rating change from pre- to post- for the comparison group was 0.50 $(t(d f=101)=-5.07, p<0.001)($ Table 1$)$.

No statistical significant difference between the mean rating change of the two groups was found for items in the questionnaire that were general questions about rising healthcare costs and the related effects on the healthcare system. For example for the question, "how would you rate your understanding of how rising healthcare costs can affect people (healthy as well as unhealthy)" students' mean score change from pre- to post- ratings for treatment group was 0.48 where as the mean score change from pretest to posttest ratings for the comparison group who were provided the textual information, without pictures, from the book in a typed document was $0.55(\mathrm{t}(101)=0.40, \mathrm{p}=0.69)$ (Table 1$)$. Cohen's effect size value $(d=0.83 ; 95 \% \mathrm{Cl}=0.42-1.23)$ suggested a large effect of the study intervention. ${ }^{25-27}$

\section{DISCUSSION}

Pharmacists, because of their accessibility, availability, and frequent contact with the consumers, are an important source of providing health insurance information to consumers. ${ }^{9,28}$ The pharmacy curriculum is designed to prepare future pharmacists to answer questions that consumers may have about their health insurance benefits. Colleges and Schools of Pharmacy cover this information about the ACA in their curriculum wherein students are exposed to the different aspects of the healthcare system in United States. The purpose of this study was to evaluate the effectiveness of an educational tool for conveying the information about the ACA.

The change in pre-post mean ratings of students in the group that read comic books was significantly higher than the change in the mean ratings of the students in the comparison group, who read a textual document of the information without pictures. This result supports the findings from other studies that found use of comic books to increase student understanding of the topic being covered. ${ }^{12,15-16}$

Versaci found that the use of comics helped students to critically examine the very definition of literature. ${ }^{12} \mathrm{He}$ mentioned that, the use of comics built students analytical and critical thinking skills. ${ }^{12}$ In the present study, comic books were reported by participants as being effective in learning of the ACA. Hosler J and Boomer KB used a similar pre-post instruction survey to measure students' learning about biology. ${ }^{15}$ Students showed a statistically significant improvement in their pre-post knowledge scores after using the comic book, suggesting that the comic may have played a role in engaging student in a positive way in learning biology. ${ }^{15}$ Nagata's study results suggested that the titles and contents of manga worked as clues to allow students to recall easily what they learned. ${ }^{16}$ Similarly, in the present study, students in the treatment group (those 
who read the comic book) showed a better understanding of ACA. It is possible that the visuals from the comic book assisted them in understanding the topic.

Results of this study should be interpreted with the following limitations in mind. The study did not assess application of student understanding of ACA to case studies or real world patient questions. Also, while there are many aspects to the ACA, not all of the aspects were asked and evaluated in this study. Only key features of the act, such as the Cadillac Tax, were asked in the questionnaire. Second, since there was a 3month gap between the pretest and the posttest, other influences, including their own professional experiences, may have affected the responses of the students. Third, the results may reflect a testing affect, as the pre-survey could have sensitized the students to the type of information that would be on the post-survey. However, the three month period between the tests could have minimized the likely impact. Lastly, the use of VAS is not common in social behavioral research. Students are usually more comfortable providing their responses on a Likert type scale rather than the VAS.

\section{CONCLUSION}

The visual rich content of the comic books proved to be an enjoyable and, innovative tool in classroom learning. The positive response from students highlight the point that pharmacy faculty could use comic books as supplemental reading in pharmacy courses.

Funding/Support: This research was made possible through the faculty start-up funds awarded by the College of Pharmacy and Health Sciences, St. John's University.

Other Disclosures: Portions of this paper were presented at the AACP Annual Meeting, Pharmacy Education 2016 in Anaheim, CA.

Acknowledgements: The authors would like to thank Ms Rosemary Brown, Ms Sherri Alarcon, Rajesh Nayak, PhD, Wenchen (Ken) Wu, PhD, for their constructive feedback and comments on the earlier versions of this manuscript.

\section{REFERENCES}

1. Centers for Disease Control and Prevention. National Center for Health Statistic. Health Insurance Coverage. 2016. Available at URL http://www.cdc.gov/nchs/data/nhis/earlyrelease/ins ur201508.pdf. Accessed on June 6, 2018.

2. Wizemann, Theresa, ed. Health Literacy Implications for Health Care Reform: Workshop Summary. National Academies Press, 2011.
3. Mach A. Individual Mandate Under the ACA. May 13, 2015. Available at URL https://www.fas.org/sgp/crs/misc/R41331.pdf. Accessed on June 6, 2018.

4. DeWalt DA, Berkman ND, Sheridan S, et al. Literacy and health outcomes. J Gen Intern Med. 2004; 19(12): 1228-1239. doi: 10.1111/j.1525-1497.2004.40153.x

5. Altman D. A Perilous Gap in Health Insurance Literacy. The Wall Street Journal. September 4, 2014. Available at URL

http://blogs.wsj.com/washwire/2014/09/04/aperilous-gap-in-health-insurance-literacy/. Accessed on June 6, 2018.

6. Cox J. Half of U.S. Adults Failt 'Health Insurance 101,' Misidentify Common Financial Terms in Plans. August 27, 2013. Available at URL

http://www.aicpa.org/press/pressreleases/2013/pag es/us-adults-fail-health-insurance-101-aicpasurvey.aspx. Accessed on June 6, 2018.

7. Greenwald LM, McCormack L, Uhrig J, \& West N. Measures and predictors of Medicare knowledge: A review of the literature. Health Care Financ Rev. 2006; 27(4): 1-12.

8. Donnelly N, Lane P, Winchester J, Powell C. An Introduction to Health Literacy and Enrollment. December 2011. Available at URL https://www.acgov.org/board/district3/documents/I ntroHealthLitAndEnrollment.pdf. Accessed on June 6, 2018.

9. Kennelty KA, Thorpe JM, Chewning B, Mott DA. Use of pharmacists or pharmacies as Medicare Part $D$ information sources. J Am Pharm Assoc. 2012; 52(6): e205. doi:10.1331/JAPhA.2012.11199.

10. Mayer RE, Sims VK. For whom is a picture worth a thousand words? Extensions of a dual-coding theory of multimedia learning. J Educ Psychol. 1994; 86(3): 389-401.

11. Carney RN, Levin JR. Pictorial illustrations still improve students' learning from text. Educ Psychol Rev. 2002; 14(1): 5-26. doi: 10.1023/A:101317630

12. Versaci R. How comic books can change the way our students see literature: One teacher's perspective. Engl. J. 2001; 91(2): 61-67.

13. Gerde VW, Foster RS. X-Men ethics: Using comic books to teach business ethics. J Bus Ethics. 2008; 77(3): 245-258. doi: 10.1007/s10551-006-9347-3

14. Short JC, Reeves TC. The graphic novel: A "cool" format for communicating to generation $Y$. Bus Comm Q. 2009; 72(4): 414-430.

15. Hosler J Boomer KB. Are Comic Books an Effective Way to Engage Nonmajors in Learning and Appreciating Science? CBE Life Sci Educ. 2011; 10(3): 309-317. doi:10.1187/cbe.10-07-0090. 
16. Nagata R. Learning biochemistry through mangahelping students learn and remember, and making lectures more exciting. Biochem Educ. 1999; 27(4): 200-203.

17. Muzumdar J. Evaluating the use of comic books as a supplemental reading to assist student learning of the dimensions of patient-centered care. INOV Pharm. 2016; 7(4):Article 2

18. Gruber, Jonathan. Health care reform: What it is, why it's necessary, how it works. $1^{\text {st }}$ edition. New York NY, Hill and Wang Publishers. 2011

19. McCarthy M, Chang C, Pickard S et al. Visual Analog Scale for Assessing Surgical Pain. J Am Coll Surg. 2005; 201(2): 245-52. doi: 10.1016/j.jamcollsurg.2005.03.034

20. Larroy C. Comparing Visual-Analog and Numeric Scales for Assessing Menstrual Pain. Behav Med. 2002; 27(4): 179-81. doi: $10.1080 / 08964280209596043$

21. Muzumdar JM, Holiday-Goodman M, Black C, Powers M. Cultural competence knowledge and confidence after classroom activities. Am J Pharm Educ. 2010; 74(8): 1-8.

22. Olejnik SF. Planning educational research: Determining the necessary sample size. J Exp Educ. 1984; 53: 40-48. Doi: 10.1080/00220973.1984.10806360

23. Pett MA, Lackey NR, Sullivan JJ. Making Sense of Factor Analysis: The Use of Factor Analysis for Instrument Development in Health Care Research. 1 edition. Thousand Oaks, CA. Sage Publications, Inc. 2003.

24. Neuman L. Social Research Methods: Qualitative and Quantitative Approaches. 6th ed. Boston, MA: Pearson Education Inc; 2006; 412.

25. Social Science Scientist. Effect size calculator for ttest. Available at URL http://www.socscistatistics.com/effectsize/Default3.a spx. Accessed on June 6, 2018.

26. Cohen J. Statistical Power Analysis for the Behavioral Sciences. $2^{\text {nd }}$ ed. Hillsdale NJ: Lawrence Erlbaum Associates; 1988.

27. Lakens D. Calculating and reporting effect sizes to facilitate cumulative science: A practical primer for ttests and ANOVAs. Frontiers in psychology. 2013; 4(863): 1-12. doi: 10.3389/fpsyg.2013.00863

28. O'Loughlin J, Masson P, Déry V, \& Fagnan D. The role of community pharmacists in health education and disease prevention: a survey of their interests and needs in relation to cardiovascular disease. Prev Med. 1999; 28(3): 324-331. doi: 10.1006/pmed.1998.0436 
Figure 1. Sample Page of Student Reading in the Treatment Group vs Comparison Group

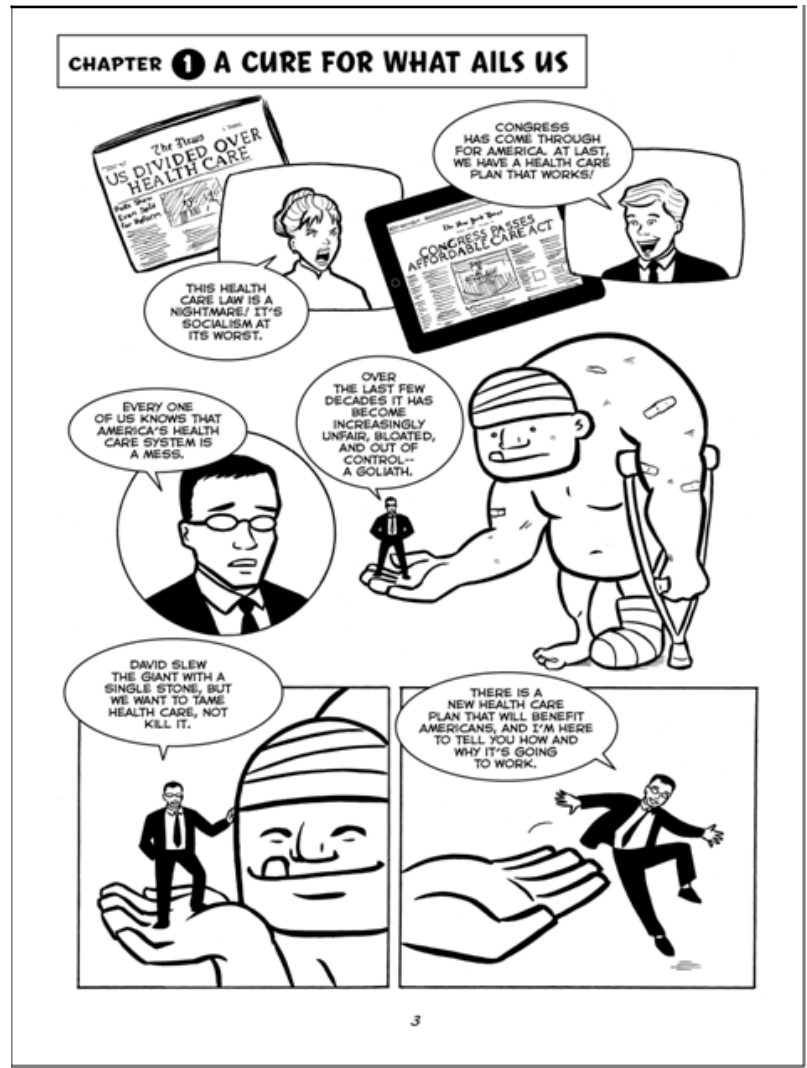

A page from the comic book read by the students in the treatment group

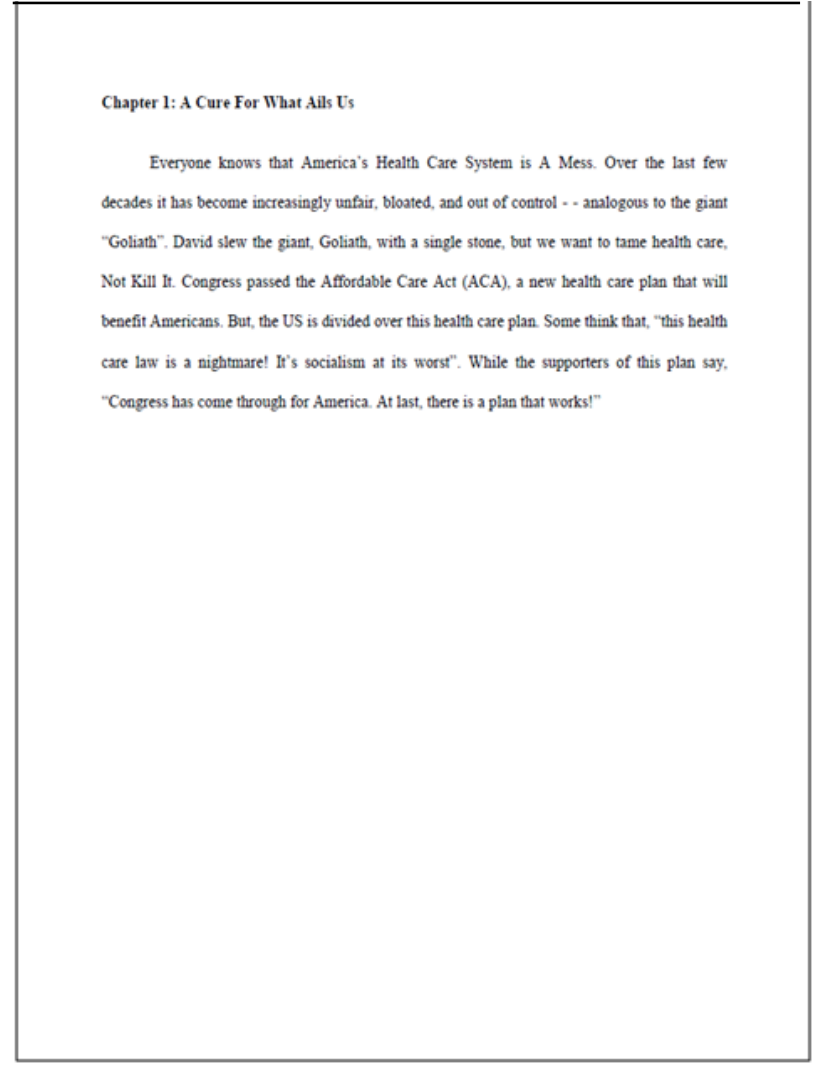

Same page from the comic book read by the students in the comparison group (text document without pictures) group 
Table 1. Perceived Confidence in Understanding Aspects of the Affordable Care Act (ACA)

Independent Sample t-test

\begin{tabular}{|c|c|c|c|c|c|c|c|c|}
\hline \multirow[b]{2}{*}{$\begin{array}{l}\text { How would you rate your understanding on the } \\
\text { following topics related to Affordable Care Act (ACA) }\end{array}$} & \multicolumn{3}{|c|}{$\begin{array}{l}\text { Treatment } \\
(\mathrm{n}=54)\end{array}$} & \multicolumn{3}{|c|}{$\begin{array}{l}\text { Comparison } \\
(n=49)\end{array}$} & \multirow[b]{2}{*}{$\begin{array}{c}t \\
(d f=101)\end{array}$} & \multirow[b]{2}{*}{$\begin{array}{c}\text { p- } \\
\text { value }\end{array}$} \\
\hline & Pre- Mean (SD) & $\begin{array}{l}\text { Post- } \\
\text { Mean } \\
\text { (SD) }\end{array}$ & $\begin{array}{l}\text { Mean } \\
\text { Change }\end{array}$ & $\begin{array}{c}\text { Pre- } \\
\text { Mean } \\
\text { (SD) }\end{array}$ & $\begin{array}{l}\text { Post- } \\
\text { Mean } \\
\text { (SD) }\end{array}$ & $\begin{array}{l}\text { Mean } \\
\text { Change }\end{array}$ & & \\
\hline $\begin{array}{l}\text { How rising healthcare costs can affect people (healthy } \\
\text { as well as unhealthy) }\end{array}$ & $3.00(0.62)$ & $\begin{array}{c}3.48 \\
(0.62)\end{array}$ & 0.48 & $\begin{array}{c}2.65 \\
(0.93)\end{array}$ & $\begin{array}{c}3.20 \\
(0.67)\end{array}$ & 0.55 & 0.40 & 0.69 \\
\hline How rising number of uninsured affect people & $2.72(0.71)$ & $\begin{array}{c}3.47 \\
(0.67)\end{array}$ & 0.75 & $\begin{array}{c}2.40 \\
(0.94)\end{array}$ & $\begin{array}{c}3.09 \\
(0.71)\end{array}$ & 0.69 & -0.36 & 0.72 \\
\hline $\begin{array}{l}\text { How hospitals cover cost of services provided to } \\
\text { uninsured people. }\end{array}$ & $2.09(0.85)$ & $\begin{array}{c}3.14 \\
(0.79)\end{array}$ & 1.05 & $\begin{array}{c}1.88 \\
(0.92)\end{array}$ & $\begin{array}{c}2.63 \\
(0.95)\end{array}$ & 0.75 & -1.34 & 0.18 \\
\hline $\begin{array}{l}\text { How does the wastage of healthcare resources affect } \\
\text { healthcare expenses }\end{array}$ & $2.90(0.83)$ & $\begin{array}{c}3.38 \\
(0.68)\end{array}$ & 0.48 & $\begin{array}{c}2.70 \\
(0.98)\end{array}$ & $\begin{array}{c}3.05 \\
(0.88)\end{array}$ & 0.36 & -0.62 & 0.54 \\
\hline $\begin{array}{l}\text { How does the "three-pronged plan" of ACA impact } \\
\text { health insurance issues of rising healthcare costs and } \\
\text { rising numbers of uninsured. }\end{array}$ & $0.98(0.82)$ & $\begin{array}{c}2.23 \\
(0.97)\end{array}$ & 1.25 & $\begin{array}{c}0.77 \\
(0.64)\end{array}$ & $\begin{array}{c}1.43 \\
(1.09)\end{array}$ & 0.66 & -2.67 & $0.01^{* *}$ \\
\hline $\begin{array}{l}\text { How do the concepts of "individual mandate" and "tax } \\
\text { penalties" in ACA affect people who do not get } \\
\text { insurance coverage }\end{array}$ & $1.35(0.89)$ & $\begin{array}{c}2.64 \\
(1.02)\end{array}$ & 1.29 & $\begin{array}{c}1.02 \\
(0.82)\end{array}$ & $\begin{array}{c}1.76 \\
(1.09)\end{array}$ & 0.74 & -2.54 & $0.01^{* *}$ \\
\hline $\begin{array}{l}\text { How the Affordable Care Act (ACA) can deliver health } \\
\text { benefits to citizens while lowering the costs }\end{array}$ & $1.74(0.89)$ & $\begin{array}{c}2.89 \\
(0.79)\end{array}$ & 1.15 & $\begin{array}{c}1.40 \\
(0.93)\end{array}$ & $\begin{array}{c}2.06 \\
(1.13)\end{array}$ & 0.65 & -2.52 & $0.01^{* *}$ \\
\hline $\begin{array}{l}\text { How does the Affordable Care Act (ACA) create } \\
\text { provisions for people in "donut hole" in Medicare Part- } \\
\text { D }\end{array}$ & $1.31(0.96)$ & $\begin{array}{c}2.70 \\
(0.90)\end{array}$ & 1.39 & $\begin{array}{c}1.01 \\
(0.79)\end{array}$ & $\begin{array}{c}1.67 \\
(1.01)\end{array}$ & 0.66 & -3.44 & 0.001 \\
\hline $\begin{array}{l}\text { How does the ACA tax credits for small businesses that } \\
\text { offer health insurance coverage for employees }\end{array}$ & $1.33(0.86)$ & $\begin{array}{c}2.66 \\
(0.91)\end{array}$ & 1.33 & $\begin{array}{c}0.90 \\
(0.65)\end{array}$ & $\begin{array}{c}1.58 \\
(0.98)\end{array}$ & 0.69 & -3.15 & 0.001 \\
\hline $\begin{array}{l}\text { How the government will offset the costs of insurance } \\
\text { with tax-credits for a certain income group }\end{array}$ & $1.49(0.92)$ & $\begin{array}{c}2.65 \\
(0.94)\end{array}$ & 1.16 & $\begin{array}{c}0.97 \\
(0.62)\end{array}$ & $\begin{array}{c}1.55 \\
(0.99)\end{array}$ & 0.58 & -2.62 & $0.01^{* *}$ \\
\hline $\begin{array}{l}\text { What are the myths and false claims made about } \\
\text { Affordable Care Act (ACA) }\end{array}$ & $1.34(0.76)$ & $\begin{array}{c}2.81 \\
(0.98)\end{array}$ & 1.46 & $\begin{array}{c}0.97 \\
(0.86)\end{array}$ & $\begin{array}{c}1.67 \\
(1.11)\end{array}$ & 0.70 & -3.89 & $0.001^{*}$ \\
\hline $\begin{array}{l}\text { What is the feature of the "Cadillac Tax" in Affordable } \\
\text { Care Act (ACA) }\end{array}$ & $0.69(0.49)$ & $\begin{array}{c}2.23 \\
(1.19)\end{array}$ & 1.54 & $\begin{array}{c}0.52 \\
(0.44)\end{array}$ & $\begin{array}{c}1.02 \\
(0.74)\end{array}$ & 0.50 & -5.07 & $0.001^{*}$ \\
\hline $\begin{array}{l}\text { What are the five key innovations of cost control } \\
\text { included in the Affordable Care Act (ACA) }\end{array}$ & $0.91(0.64)$ & $\begin{array}{c}2.42 \\
(0.80)\end{array}$ & 1.51 & $\begin{array}{c}0.69 \\
(0.70)\end{array}$ & $\begin{array}{c}1.26 \\
(0.89)\end{array}$ & 0.57 & -4.93 & $0.001^{*}$ \\
\hline $\begin{array}{l}\text { What are provisions in Affordable Care Act (ACA) for } \\
\text { senior citizens }\end{array}$ & $1.24(0.83)$ & $\begin{array}{c}2.77 \\
(0.71)\end{array}$ & 1.53 & $\begin{array}{c}1.00 \\
(0.75)\end{array}$ & $\begin{array}{c}1.57 \\
(1.07)\end{array}$ & 0.57 & -4.43 & 0.001 \\
\hline
\end{tabular}

The scale used was a Visual Analog Scale (VAS). VAS was 5 inches in length.

Markings at 0 inches denoted "No understanding of the topic", whereas markings at 5 inches denoted "Complete understanding of the topic".

** $p<0.05 ;{ }^{*} p<0.01$ 